Erratum

\title{
Erratum: Ismail, I.T.; et al. Inborn Errors of Metabolism in the Era of Untargeted Metabolomics and Lipidomics. Metabolites 2019, 9, 242
}

\author{
Israa T. Ismail ${ }^{1,2}$, Megan R. Showalter ${ }^{2}$ and Oliver Fiehn ${ }^{2, *(1)}$ \\ 1 National Liver Institute, Menoufia University, Shebeen El Kom 55955, Egypt; israataher2015@gmail.com \\ 2 NIH West Coast Metabolomics Center, University of California Davis, Davis, CA 95616, USA; \\ mshowalter@ucdavis.edu \\ * Correspondence: ofiehn@ucdavis.edu
}

Received: 6 December 2019; Accepted: 30 December 2019; Published: 6 January 2020

check for updates

The authors wish to make the following correction to this paper [1].

Reference [2] was cited in connection with concept Figure 5, but must be also cited in our Figure 5 legend. Figure 1 of Reference [2] was re-used as part of our concept Figure 5.

The correct Figure 5 legend should be:

Figure 5. Improvement of IEM diagnosis tests using untargeted metabolomics. Re-use of Figure 1 from [176], with permission from the publisher.

The authors would like to apologize for any inconvenience caused to the readers by these changes.

\section{References}

1. Ismail, I.T.; Showalter, M.R.; Fiehn, O. Inborn errors of metabolism in the era of untargeted metabolomics and lipidomics. Metabolites 2019, 9, 242. [CrossRef] [PubMed]

2. Burrage, L.C.; Thistlethwaite, L.; Stroup, B.M.; Sun, Q.; Miller, M.J.; Nagamani, S.C.S.; Craigen, W.; Scaglia, F.; Sutton, V.R.; Graham, B.; et al. Untargeted metabolomic profiling reveals multiple pathway perturbations and new clinical biomarkers in urea cycle disorders. Genet. Med. 2019, 21, 1977-1986. [CrossRef] [PubMed]

C 2020 by the authors. Licensee MDPI, Basel, Switzerland. This article is an open access article distributed under the terms and conditions of the Creative Commons Attribution (CC BY) license (http://creativecommons.org/licenses/by/4.0/). 